\title{
Consciência histórica sobre a África e a cultura afro-brasileira
}

Historical consciousness about Africa and the Afro-Brazilian culture

Luíza Vieira Maciel ${ }^{\star}$

Claricia Otto ${ }^{\star *}$

\section{RESUMo}

Este artigo resulta de pesquisa que objetivou compreender aspectos da consciência histórica de alunos de uma escola municipal por meio da análise de um conjunto diversificado de atividades que tomou como foco a história da África e a cultura afro-brasileira. Foi possível identificar diferentes sentidos históricos produzidos pelos alunos participantes da pesquisa, dentre os quais se destacaram referências à pobreza, violência e subdesenvolvimento do continente africano. Apesar disso, os alunos também indicaram a diversidade de suas riquezas naturais e culturais, bem como a força de vontade de sua população. Constatamos que essas perspectivas foram elaboradas com base em informações provenientes de diferentes espaços, principalmente a televisão, os filmes e a escola, com destaque para as aulas de História.

Palavras-chave: consciência histórica. História da África; cultura afro-brasileira.
This article results of research that intended to understand aspects of the historical consciousness of students of a municipal school through the analysis of a diverse set of activities that focused on the history of Africa and the AfroBrazilian culture. It was possible to identify different historical meanings produced by students participating in the research, among which stood out references to poverty, violence and underdevelopment of African continent. Despite this, the students also indicated the diversity of their natural and cultural wealth, as well as the will power of its population. We note that these perspectives have been prepared based on information from different areas, among which stand out the television, movies and the school, specifically the lessons of History.

Keywords: Historical consciousness; History of Africa; Afro-Brazilian culture.

Abstract

* Mestra em Educação (UFSC). Doutoranda do Programa de Pós-Graduação em Educação da Universidade Federal de Santa Catarina (UFSC). Florianópolis, SC, Brasil.luiza.luidy@gmail.com

** Doutora em História. Professora do Departamento de Metodologia de Ensino e do Programa de Pós-Graduação em Educação da UFSC. Florianópolis, SC, Brasil. clariciaotto@gmail.com 
Porque tudo o que eu havia lido eram livros em que os personagens eram estrangeiros, fui convencida de que livros naturalmente tinham de ter estrangeiros e ser sobre coisas com as quais eu não poderia me identificar. Mas tudo mudou quando eu descobri livros africanos ... Tive uma virada na minha percepção sobre literatura. Percebi que pessoas como eu, meninas com pele de cor de chocolate, cujo cabelo crespo não dava pra fazer rabo de cavalo, também poderiam existir na literatura. ${ }^{1}$

A epígrafe é da conferência intitulada "O perigo de uma história única", proferida pela escritora nigeriana Chimamanda Adichie, em 2009, em evento realizado pela Technology, Entertainment and Design (TED), uma organização não governamental. Essa conferência ajuda-nos a problematizar as formas pelas quais construímos estereótipos de pessoas e/ou lugares. Adichie chama a atenção para o perigo de termos uma única forma de contar histórias como sendo a verdadeira.

Entendemos que, em certa medida, os sentidos das indagações de Chiamamanda Adichie podem ser trazidos para o cenário educacional brasileiro atual no qual é possível identificar a propagação de discursos que objetivam constituir o ambiente escolar como um espaço privilegiado para a educação das relações etnorraciais, ou seja, para a constituição de histórias plurais. Entre esses, destaca-se a aprovação da Lei $n^{\circ} 10.639 / 2003$, a qual garantiu a obrigatoriedade curricular de história e cultura africana e afrodescendente para toda a educação básica nacional.

Investigar as especificidades que constituem os processos de implementação dessa política em diferentes espaços escolares, além de valorizar e divulgar tais iniciativas, é também uma estratégia frutuosa para inquirir sobre como sujeitos escolarizados aprendem história em diferentes contextos. Diante de tal consideração, o presente artigo revisita elementos trabalhados em pesquisa concluída em 2014.

Nesta pesquisa, operamos com o conceito de consciência histórica cunhado por Jörn Rüsen (2001; 2006; 2007a; 2007b), com a finalidade de subsidiar a análise dos conhecimentos históricos de jovens estudantes. $\mathrm{O}$ autor define consciência histórica como "a soma das operações mentais com as quais os homens interpretam sua experiência da evolução temporal de seu mundo e de si mesmos de forma tal que possam orientar, intencionalmente, sua vida 
prática no tempo" (Rüsen, 2001, p.57). Nessa direção, a consciência histórica diz respeito a uma capacidade humana cognitiva de compreender-se e orientar-se como sujeito de um determinado tempo histórico. Essa capacidade igualmente caracteriza uma necessidade, haja vista que interpretar o presente, na interação com o passado, numa perspectivação de futuro, é crucial para a manutenção da vida social cotidiana.

Dado que não existe uma definição unânime entre os diferentes autores que operam com o conceito de consciência histórica, nossa opção pela perspectiva de Jörn Rüsen se deu em função de que sua proposição remete a "algo universalmente humano, dado necessariamente junto com a intencionalidade da vida prática dos homens ... a consciência histórica enraíza-se, pois, na historicidade intrínseca à própria vida humana prática" (Rüsen, 2001, p.78). A adesão a essa perspectiva universalista é uma questão complexa entre os teóricos que trabalham com o referido conceito. Autores como Ariès (1989) e Gadamer (1998) vão de encontro a essa percepção e compreendem que a consciência histórica não seria uma capacidade humana, mas sim um princípio tornado possível por meio de um processo histórico, constituindo-se, dessa forma, como uma "tomada de consciência". Esse advento cognitivo teria sido possibilitado pelo avanço do pensamento filosófico na modernidade, por meio do qual se pôde atingir um nível de afastamento interpretativo que tornou plausível relativizar as experiências humanas, considerando os diversos contextos temporais em que ocorreram.

Cerri (2001) alinha-se às ideias de autores como Heller (1993) e Rüsen (2001), os quais compreendem a consciência histórica como algo inerente à existência humana, a qual, para além de uma capacidade cognitiva, constitui-se como uma necessidade para a vida prática. Nesse alinhamento, Cerri (2001, p.96) indica que busca compreender a consciência histórica "como perpassando o especialista e o homem comum, ainda que entre estes estabeleça-se uma relação que pode ter muitas características, que vão de uma hierarquia de saber até uma horizontalidade na vivência da consciência da história”.

Tal perspectiva traz significativas contribuições para as investigações que se debruçam sobre a aprendizagem histórica. Para além dos grandes acontecimentos e explicações científicas, o conhecimento histórico escolar passa a ser concebido como espaço ampliado para o estudo da experiência, contemplando 
sujeitos que tradicionalmente não eram considerados nas narrativas históricas oficiais, incluindo professores, estudantes e suas concepções sobre a História.

Tomando por pressuposto que a consciência histórica é uma operação na qual se relacionam experiências e intenções com o objetivo de orientação temporal, procurou-se inquirir como alunos do Ensino Fundamental relacionavam saberes e experiências ao elaborar seu quadro interpretativo acerca da história africana e afrodescendente. Dessa forma, a instrumentalização do conceito procurou identificar o que esses jovens conheciam sobre tal conteúdo e, também, como operavam seus conhecimentos ao desenvolverem considerações sobre o tema em questão, com o fim de identificar quais sentidos de interpretação histórica os alunos apresentavam sobre a história do continente africano.

O campo selecionado para o desenvolvimento dessa problemática investigativa foi a Escola Básica Municipal Dilma Lúcia dos Santos, localizada no bairro da Armação do Pântano do Sul, em Florianópolis (SC). A identificação da trajetória de trabalho pela educação das relações etnorraciais, em desenvolvimento na Instituição desde o fim da década de 1990, foi um dos principais elementos que condicionaram o interesse em realizar a pesquisa nessa escola. Segundo consta no Projeto Político Pedagógico referente a 2010, a educação etnorracial constitui-se como um dos eixos curriculares que orientam as práticas educativas, juntamente com a educação ambiental e a formação para a cidadania.

Em diálogo com a equipe pedagógica e com uma das professoras de História, foram selecionados como sujeitos da pesquisa os alunos matriculados nas séries finais do Ensino Fundamental ( $5^{\mathrm{a}}$ à $8^{\mathrm{a}}$ série/ $6^{\circ}$ ao $9^{\circ}$ ano). $\mathrm{O}$ envolvimento desses sujeitos no desenvolvimento da pesquisa demandou que se dedicasse atenção às questões éticas, conforme postulado pelo Comitê de Ética em Pesquisa com Seres Humanos (CEPSH), da Universidade Federal de Santa Catarina (UFSC), amparado na Resolução nº 466/2012, do Conselho Nacional de Saúde. Dessa forma, todos os sujeitos envolvidos na investigação e seus respectivos responsáveis validaram seu aceite por meio do Termo de Consentimento Livre e Esclarecido (TCLE).

A produção dos aportes metodológicos da investigação esteve centrada no objetivo de instigar a produção de expressões da consciência histórica dos jovens alunos, possibilitando constatar as diferentes vertentes de informação 
e suas diversas perspectivas de interpretação a respeito da história africana. Considerando a complexidade de elementos relacionados no desenvolvimento da consciência histórica, optou-se pela divisão dos procedimentos metodológicos em duas etapas. A primeira delas foi desenvolvida com três turmas das séries finais do Ensino Fundamental: $6^{\circ}$ ano, $7^{\circ}$ ano e uma $8^{a}$ série, somando 71 alunos.

Nessa primeira etapa, o instrumento metodológico selecionado consistiu em uma atividade escrita, de desenvolvimento individual, contendo cinco questões. A proposta da atividade levava em consideração que estudantes de diferentes anos escolares deveriam ser capazes de desenvolvê-la. Planejada com o objetivo de sondagem inicial, as questões procuravam identificar saberes diversos dos alunos sobre o continente africano e também os principais meios a partir dos quais esses sujeitos obtinham informações sobre a temática em foco.

Finalizada a primeira intervenção com os alunos, os dados produzidos foram quantificados e analisados, servindo como eixos de orientação para o planejamento das demais atividades desenvolvidas. $\mathrm{Na}$ análise desse primeiro montante de fontes, consideramos a necessidade de aprofundar elementos sobre a compreensão histórica dos alunos com relação ao continente africano.

Empreendemos, portanto, uma segunda estratégia metodológica, na qual as atividades foram organizadas em uma sequência de encontros com um número reduzido de alunos. Dessa maneira, foi possível criar um ambiente mais intimista e propositivo para diálogos, no qual se buscou apreender de forma qualitativa a consciência histórica dos sujeitos participantes. Foram constituídos dois pequenos grupos de discussão sobre a África, compostos por dez alunos oriundos das três turmas participantes da primeira etapa investigativa. Cada um desses grupos participou de três encontros, com duração média de duas horas, nos quais foram desenvolvidas atividades diversificadas, como interpretações de texto, produções narrativas, discussões direcionadas, dinâmicas de grupo e atividades didáticas.

Ao serem relacionados os dados obtidos nas duas etapas de intervenção com os alunos, foi possível perceber que as expressões de suas consciências históricas eram operadas e apresentadas de diferentes formas, evidenciando um processo de mediação de informações e interpretações históricas a propósito do continente africano. Além de apresentarem uma diversidade de percepções sobre a África, os alunos também indicaram espaços privilegiados por 
meio dos quais adquiriam informações sobre o referido tema, dentre os quais se destacaram a escola, os filmes e a televisão. Essas diferentes perspectivas indicaram convergências e rupturas nas ideias apresentadas por alunos de diferentes séries e idades, sugerindo que essas variáveis não são determinantes para circunscrever as formas de apropriação do conhecimento histórico desenvolvidas por esses jovens estudantes. Nos tópicos que se seguem, destacamos os principais sentidos históricos de interpretação a respeito da África identificados nas respostas dos alunos ao longo do desenvolvimento das duas etapas da investigação.

\section{Perspectivas dos alunos: África é Pobre, subdesenvolvida, DE NATUREZA ABUNDANTE, TEM PESSOAS NEGRAS}

Para a primeira etapa da pesquisa, foi criado um instrumento investigativo composto por cinco questões. Esse instrumento foi aplicado durante a aula de História das três turmas e teve por objetivo desenvolver uma sondagem inicial sobre as ideias dos alunos, procurando identificar saberes diversos acerca do continente africano e quais os principais meios dos quais recebiam informações a respeito da referida temática.

As respostas apresentadas para a primeira atividade indicaram, de maneira geral, que alunos de diferentes séries compartilhavam diversas perspectivas de compreensão sobre a África. Além disso, as respostas dos alunos com mais idade não foram necessariamente mais precisas em relação àquelas proferidas pelos alunos com menos idade. Essa questão pode ser percebida, por exemplo, nas respostas apresentadas pelos alunos para a primeira questão da atividade. O enunciado solicitava que os participantes localizassem, geograficamente, o continente africano em uma reprodução do mapa mundial na qual todos os continentes e oceanos apareciam representados em branco, desprovidos de qualquer tipo de legenda. Para tanto, os alunos deveriam colorir a extensão completa correspondente ao continente africano. Comparativamente, os alunos do $6^{\circ}$ ano obtiveram um maior número de acertos com relação aos alunos do $7^{\circ}$ ano e da $8^{\mathrm{a}}$ série.

Outro elemento que chamou a atenção durante a sistematização dos dados foi o fato de que diversos alunos, oriundos de todas as séries, pintavam apenas parcialmente o continente africano, mantendo em branco o território 
referente à ilha de Madagascar. Dessa maneira, foi necessário criar uma categoria específica para os alunos que localizaram o território africano apenas em sua parte continental, diferenciando-os daqueles que coloriram a extensão completa que representava o continente no mapa, conforme pode ser percebido no Gráfico 1.

Gráfico 1 - Respostas dos alunos quanto à

localização do continente africano no mapa mundial

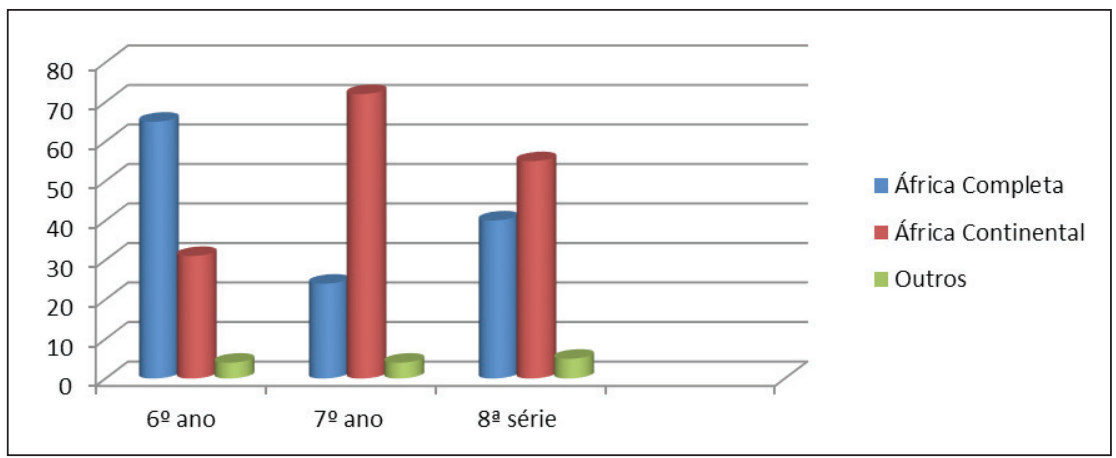

Fonte: Elaborado pelas autoras com base nas atividades realizadas pelos alunos (2013).

Se considerada a pouca expressividade do número de sujeitos que não soube identificar a localização da África, é possível afirmar que, ainda que eles não possuam uma concepção precisa e específica sobre os territórios e países africanos, apresentam um acervo interpretativo que permite uma noção espacial geral acerca do continente. Além disso, a relativa convergência da representação parcial do território entre os alunos indica que essa noção não especializada serve de embasamento para orientar suas interpretações e também para situar as informações que recebem sobre o continente em seu cotidiano.

Essa constatação é endossada pelas respostas apresentadas pelos alunos nas quais afirmam que o acesso a informações sobre a temática em questão é feito com pouca regularidade. A maioria dentre os alunos das três turmas sinalizou que, em seu cotidiano, ouve, às vezes, falar sobre a África, ou então, raramente. No total da amostra de 71 alunos, apenas dois sinalizaram que recebem informações sobre esse tema várias vezes, nenhum sinalizou todos os dias e sete alunos apontaram que nunca recebem informações sobre o referido continente. 
Além da frequência de entrarem em contato com informações acerca da África, os alunos foram questionados quanto aos principais meios de acesso às informações que possuem sobre o continente. Foi solicitado que indicassem, em uma lista na qual constavam diferentes linguagens e meios de comunicação, quais eram os três principais veículos responsáveis por apresentar informações sobre a África em seu cotidiano. As respostas obtidas para essa questão indicaram significativa convergência entre as três turmas: sobressaíram em todas elas as referências à televisão, escola e filmes. Posteriormente, durante a etapa de aprofundamento, os alunos detalharam os temas escolares, programas televisivos e títulos dos audiovisuais conhecidos que abordam a África, além de terem exprimido suas opiniões a respeito de cada um dos veículos citados.

Além dessas três questões, o instrumento de pesquisa propunha atividades que exigiam a elaboração de respostas dissertativas. Em uma delas, os participantes deveriam exprimir suas concepções sobre o continente africano, complementando as seguintes frases: “A África é... Os africanos são... Quando eu ouço a palavra África, penso em...”. Ademais, propomos uma segunda questão escrita, na qual foram expostas cinco séries temáticas de fotografias (Figuras 1 a 5), agrupadas nos seguintes tópicos: cidades, habitações, natureza, construções arquitetônicas antigas e crianças. Essas fotografias foram extraídas do acervo digital da Casa das Áfricas (Instituto Cultural de Formação e de Estudos sobre Sociedades Africanas) por Souza (2011) e representam lugares e pessoas contemporâneas de diversos países da África. Todavia, as fotografias foram apresentadas sem título e sem legenda, ou seja, nada foi informado aos alunos a respeito da origem das fotografias e solicitamos que identificassem as que acreditavam terem sido produzidas no continente africano, justificando sua opinião pelo "sim" ou pelo "não" para cada uma das imagens das Figuras 1 a 5.

Figura 1 - Cidades

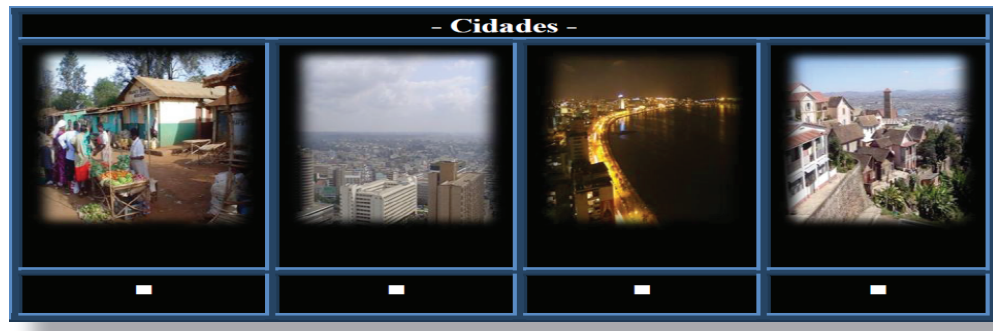

Fonte: Souza (2011, p.335). 
Figura 2 - Habitações

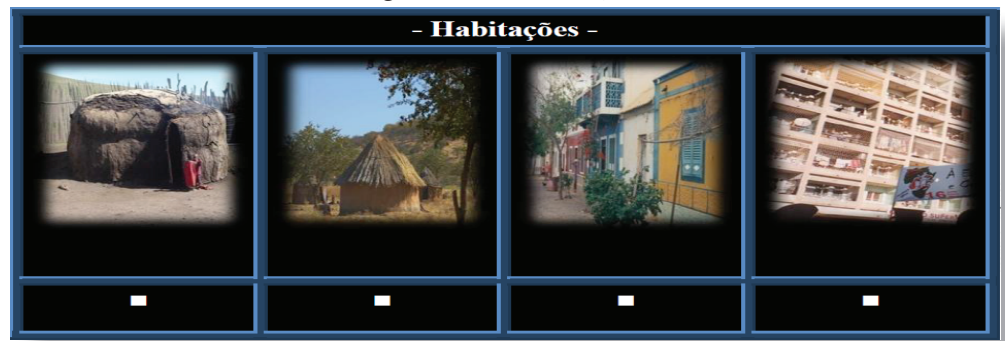

Fonte: Souza (2011, p.335).

Figura 3 - Natureza

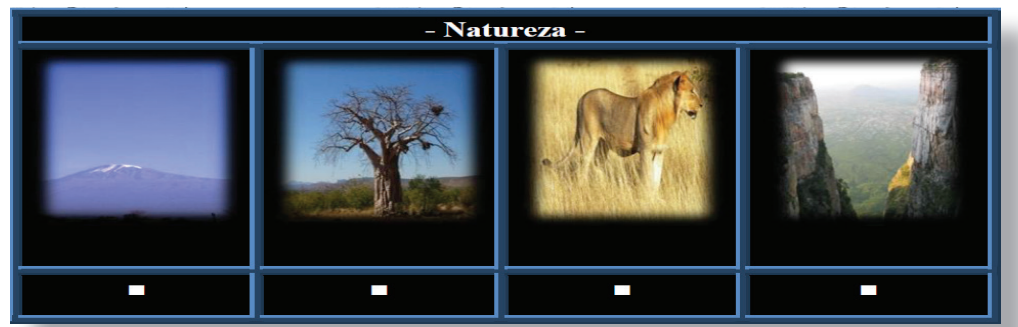

Fonte: Souza (2011, p.334).

Figura 4 - Construções arquitetônicas antigas

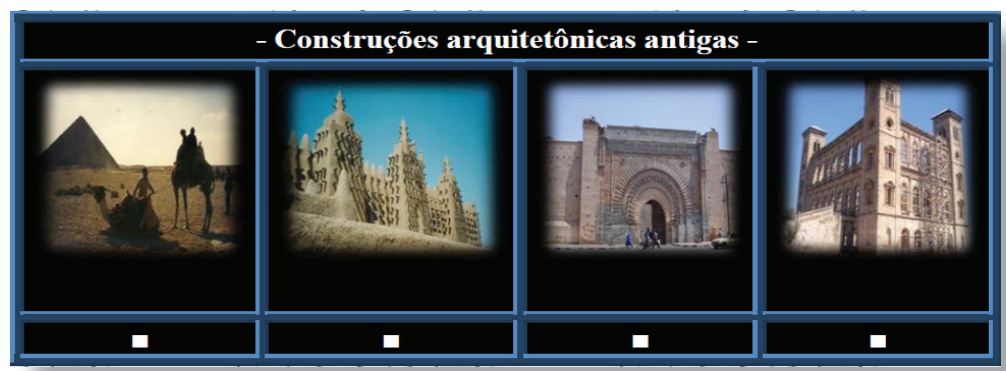

Fonte: Souza (2011, p.334). 
Figura 5 - Crianças

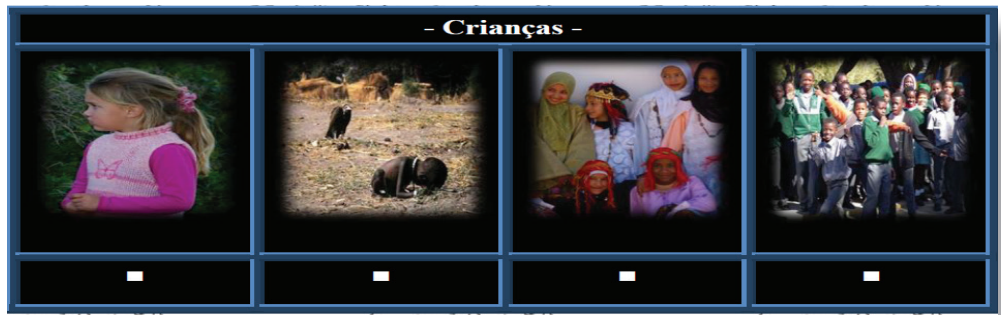

Fonte: Souza (2011, p.335).

Para ambas as questões sobre as quais solicitamos que os alunos expusessem suas concepções, sobressaíram-se as referências à África como um continente pobre e pouco desenvolvido, onde é possível identificar diferentes mazelas sociais, como fome e escassez de água. Esse ponto de vista foi um dos mais recorrentes nas respostas apresentadas pelas três turmas. Outros caracterizaram os africanos como "guerreiros", indicando uma perspectiva de superação, própria a esses povos, no que concerne às adversidades por eles vividas. A seguir, listamos fragmentos desse conjunto de perspectivas apresentadas pelos alunos:

\section{ÁFRICA POBRE E SUBDESENVOLVIDA}

Uma casa precária, de más condições, infelizmente a África sofre muito com isso. (P.C., $8^{\text {a }}$ série). ${ }^{2}$

Eu acho que não tem ruas urbanas lá. (M.L.R.C., $8^{\mathrm{a}}$ série)

Um continente pobre e com poucos recursos na área da saúde, educação e principalmente coisas relacionadas à água. (M.E.M., 8 a série.)

Uma menina bem vestida, não é da África. (V.S.L., $7^{\circ}$ ano)

Um lugar humilde, que passa por várias necessidades. (M.R.M., $6^{\circ}$ ano)

Um povo que luta mesmo nas piores dificuldades. (P.C., $8^{\text {a }}$ série)

Um povo guerreiro com muitas dificuldades para enfrentar mas mesmo assim não desistem. (L.R.M., $8^{\mathrm{a}}$ série)

Morenas, trabalham muito, se esforçam e são guerreiras. (M.L.C.G., $6^{\circ}$ ano) 
Em contrapartida, as referências às riquezas naturais africanas também estiveram presentes nas respostas dos alunos, os quais indicaram leões, savanas e selvas como elementos conhecidos sobre o continente. Entre as respostas incluídas nessa perspectiva, alguns alunos indicaram que a abundância da flora e da fauna africana possui relação direta com seu escasso desenvolvimento urbano e tecnológico.

\section{ÁfricA COMO LOCAL DE NATUREzA ABUNDANTE}

Eu acho que essa foto é na África pelo fato de lá ter muitos animais. (K.A.B.G., $6^{\circ}$ ano)

Eu acho que é porque tem um leão solto e na África é fácil ver isso. (P.R.A.G., $7^{\circ}$ ano)

A África é pobre no comércio e urbanização, mas é muito rica em natureza e lazer ambiental. (L. C., $7^{\circ}$ ano)

Eu escolhi as imagens 2 e 3 porque animais e árvores me fazem lembrar a África, mesmo eu não sabendo tudo o que existe lá. Essas coisas me lembram a África porque eu vejo bastante documentários sobre a África. (J.B., $8^{\text {a }}$ série)

Um continente pobre mas com muita natureza. (I.K., $7^{\circ}$ ano)

Um lugar pouco desenvolvido e ao mesmo tempo bonito por causa da natureza. (A.L., $8^{a}$ série)

Nessas passagens, é possível perceber que a compreensão histórica desses alunos opera em termos de oposição entre natureza e desenvolvimento. Considerando que os sujeitos desta pesquisa estão inseridos em um contexto de vida urbano na capital catarinense, é possível afirmar que compreendem a abundância de recursos naturais africanos como um sintoma de atraso daquele continente, interpretando o desenvolvimento urbano como um ideal a ser buscado por toda a humanidade. Rüsen (2012) desenvolve uma discussão relativa à categoria histórica do progresso que colabora com a análise dessa perspectiva presente nas respostas dos alunos. Nessa interpretação, o progresso é uma "figura de pensamento" que influencia a orientação para a vida prática e a compreensão do outro e de si mesmo: 
As gerações mais jovens realizam somente para si a cultura do pensamento progressista - encravadas em suas condições de vida - como um estimulante de um estilo de vida próprio. Elas encontram nessa cultura um ponto de vista central com o qual interpretam as experimentadas e desejadas mudanças temporais de suas próprias condições de vida. O progresso como figura de pensamento é um fato social, um fator da experiência humana de vida ativo mentalmente. (Rüsen, 2012, p.178)

Essa perspectiva autocentrada de interpretação foi identificada novamente entre os alunos que participaram da segunda etapa de atividades com os pequenos grupos, constituindo-se como uma característica significativa de suas consciências históricas, conforme será destacado adiante.

Ainda com relação às respostas apresentadas para o primeiro instrumento, outros alunos definiram os africanos pelo fenótipo negro. Dentre esses, alguns utilizaram o termo "afrodescendente". Esse fato evidencia a noção dos alunos sobre a adoção consideravelmente recente do termo nas mídias, na legislação e espaços de escolarização.

\section{AFriCANOS COMO NEGROS/NÃO BRANCOS}

Uma comunidade negra, parece sim estar na África. (J.M.P., 8a série)

A criança é branca. A população africana é negra. (M.E.M., $8^{\mathrm{a}}$ série)

Essa é da África porque na África os moradores são negros. (G.N.V., $7^{\circ}$ ano)

Porque na África as crianças são negras e pobres. (R.F.G.C., $7^{\circ}$ ano)

Os africanos são... afrodescendentes e livres. (M.L.S., $6^{\circ}$ ano)

Além desses, ainda foi possível identificar um número menos expressivo de alunos que apresentaram respostas críticas a uma visão homogênea sobre o continente africano. Nessas passagens, foi destacada a existência de países pobres e ricos, ou então, evidenciadas as expressões culturais e contribuições históricas dos povos africanos. Alguns alunos, em sua maioria da $8^{\text {a }}$ série, apresentaram respostas que sugerem uma compreensão de que os africanos formam grupos diversos. 


\section{ÁFRICA COMO DIVERSIDADE}

Eu acho que é da África porque na África não é só pobreza, existe muita riqueza. (G.S., 8 $8^{\text {a }}$ série)

Só porque são negros, não significa que são africanos. (P.C., $8^{\mathrm{a}}$ série).

$\mathrm{Eu}$ acho que todas, porque a África tem vários tipos de classe. (L.G., $7^{\circ}$ ano)

Mas também eu sei que lá na África tem uma parte mais rica. (E.E.S.A., $7^{\circ}$ ano)

A [sic] muitos lugares da África com dinheiro, a África não é só pobreza. (G.S., $8^{\mathrm{a}}$ série)

Eu assinalei as quatro imagens, porque como eu já falei pode haver pobreza em diferentes países, sofrimento, mas também pode haver outras pessoas com diferentes casas. (L.B., $7^{\circ}$ ano)

Povos que têm característica negra, politeísta e humilde. (E.H.N., 8a série)

Em uma análise geral, apesar de a maior parte dos alunos ter justificado suas impressões com base em referências sobre a pobreza africana, é possível afirmar a existência de uma diversidade de compreensões sobre o continente entre os sujeitos participantes da primeira etapa da investigação. Tal afirmação pode ser identificada nas passagens que foram críticas a essa visão, que, apesar de terem sido em menor número, estiveram presentes, além de terem sido consideravelmente retomadas na segunda etapa da investigação. Ademais, a variedade de categorias necessárias para distinguir os pontos de vista identificados entre as respostas indica, no mínimo, diferentes estratégias utilizadas por esses sujeitos para operar os conhecimentos que têm sobre o continente africano.

Ainda que sejam levadas em conta as limitações do primeiro instrumento empregado, essa etapa de sondagem foi considerada eficiente, em especial, por dois motivos: primeiramente, pelo diagnóstico das turmas investigadas, possibilitando apreender ideias e interpretações gerais que esses sujeitos desenvolveram sobre a África e seus descendentes. O instrumento igualmente foi produtivo para a definição de itinerários investigativos acionados durante a segunda etapa metodológica, na qual se estabeleceu o objetivo de aprofundamento da análise quanto à compreensão histórica, o que possibilitou, dessa forma, identificar os diferentes sentidos de interpretação da consciência histórica desses alunos. 


\section{PERSPECTIVAS DOS ALUNOS: “NÓS” DESENVOLVIDOS VERSUS “OUTROS” SUBDESENVOLVIDOS, A CRÍTICA ÀS MÍDIAS, O PAPEL DA ESCOLA E A INTERAÇÃO COM OS COLEGAS}

Para a segunda etapa, organizamos o trabalho por encontros com pequenos grupos, nos quais foi desenvolvido um conjunto diversificado de atividades. Nesses encontros, sediados na biblioteca da escola, os alunos participaram de atividades de leitura de textos históricos e literários, interpretação de vídeos, discussões orientadas, dinâmicas de grupo e, além disso, desenvolveram suas próprias narrativas escritas, tendo sempre a temática africana como eixo central.

Dessa maneira, o objetivo era constituir um conjunto de instrumentos metodológicos diferenciados, que possibilitassem contemplar múltiplos perfis de alunos. Durante o desenvolvimento das atividades, a ideia foi explorar, por meio de diferentes estratégias, suas capacidades interpretativas, ampliando, dessa forma, as possibilidades de constituição de dados significativos junto aos grupos com relação à consciência histórica sobre a África e os afrodescendentes. Com esse objetivo, procuramos aprofundar elementos que não puderam ser identificados na primeira etapa, tomando como estratégia recursos que fomentassem capacidades de oralidade e a escrita dos alunos, perpassando outras características, como desenvoltura para o trabalho em grupo ou individual, exercícios de criatividade e também de síntese.

Com base em discussões, nas narrativas escritas e nas respostas produzidas para as diferentes dinâmicas e atividades realizadas, foi possível identificar diferentes interpretações de sentido histórico entre os alunos, as quais foram analisadas à luz do conceito de consciência histórica (Rüsen, 2001). A seguir estão destacadas as principais perspectivas apresentadas pelos alunos durante os encontros entre os pequenos grupos, especialmente aquelas que endossaram ou complementaram dados que haviam sido identificados por meio do primeiro instrumento investigativo.

Durante os encontros, ao apresentar suas ideias sobre o continente africano, diversos alunos desenvolveram suas considerações com base em perspectivas autocentradas de interpretação, nas quais caracterizaram o continente africano embasados em referências pessoais, como suas experiências e memórias. Nessas discussões, os alunos supervalorizaram aspectos do seu próprio 
cotidiano, como o acesso ao consumo de tecnologias e entretenimento, em oposição ao que acreditam existir na África, a qual foi caracterizada como um local isolado e desestruturado. Entre os exemplos, estão as discussões nas quais aproximaram e distanciaram os africanos de suas próprias identidades, ou também, quando fizeram referências aos bairros do entorno da escola a fim de conjecturar sobre a realidade dos jovens africanos.

$\mathrm{Na}$ África eles não saem à noite? Na África eles namoram, assim? ... Aqui nas baladas a gente ainda não pode ir, mas eu saio de noite. Vou no centrinho, vou no luau, vou em um monte de coisas. (L., $7^{\circ}$ ano)

Eu fico pensando, como é que seria viver lá, não ter telefone, televisão... sem internet! Imagina viver sem internet! (S.S.S., $8^{\text {a }}$ série)

Sem produto de cabelo, sem maquiagem, ai, muito difícil. (L., $7^{\circ}$ ano)

Eu não me vejo morando na África porque assim, eu já me coloquei no lugar, eu já pensei, por exemplo, eu estudando na escola lááá do Pântano. ${ }^{3}$ Todo mundo lá ia me chamar de nojenta, de metida. (L., $7^{\circ}$ ano)

Eles iam pegar no pé dela total. Pode ter certeza. (S.S.S., 8 $8^{\text {a }}$ série)

Nessas passagens, é possível identificar que a interpretação que é feita sobre o outro está imbricada pela noção que se tem de si mesmo, considerando que, ao definir o que é diferente, é necessário estabelecer características para a própria identidade. Rüsen (2009) compreende que tal perspectiva é uma parte constituinte da elaboração dos sentidos de orientação histórica.

A localização do eu, em termos de realidade territorial da vivência assim como em termos da posição mental do eu no cosmos de coisas e seres, possui uma dimensão temporal. É apenas por essa dimensão temporal que a posição do eu torna-se fixa como um habitat cultural de grupos e indivíduos. Situando eles mesmos, os sujeitos traçam as fronteiras com outros e a sua alteridade nas dimensões local e temporal de um mundo comum, no qual eles se encontram e se diferenciam uns dos outros de modo a eles mesmos tornarem-se sujeitos. Tais fronteiras são normativamente determinadas e sempre carregadas de valor. (Rüsen, 2009, p.174)

Seguindo essa linha interpretativa, é possível compreender, por exemplo, de que forma as características diminutas e provincianas do bairro da Armação 
do Pântano do Sul, local onde a escola fica localizada e no qual reside a maioria dos participantes, foram pormenorizadas na interpretação da aluna quando afirmou que na África não deveriam existir opções de lazer como as que se encontram disponíveis em seu bairro. Considerando que nesse espaço ela desenvolve vivências de uma adolescência urbana, suas experiências colaboram para que seu entorno seja compreendido como um centro desenvolvido, especialmente quando são estabelecidas comparações com a África, a qual, de acordo com ela, é carregada de sentidos antagônicos aos da urbanização. Novamente, segundo Rüsen (2009), a memória histórica é um elemento legitimador para as experiências e constituição de identidades.

É parte da abordagem intencional do passado pela memória histórica e pelo pensamento histórico a sujeição a uma avaliação positiva de tudo o que conta como pertencente a um tempo, mundo e ordem mundana individual legitimadora de sua autocompreensão. Dessa forma, aspectos negativos da experiência do tempo com relação ao mundo e a si mesmo são eclipsados do mundo individual e do espaço interior de si mesmo; eles são arrastados para a periferia e mantidos a distância. A diferença produtora de identidade entre o eu e o outro está operando em cada memória, e qualquer esforço de lembrança é em si mesmo uma relação normativa assimétrica. (Rüsen, 2009, p.147)

No caso apresentado anteriormente, a interpretação da própria realidade com base em referenciais de "desenvolvimento urbano", em oposição à compreensão do outro como "pouco desenvolvido", indica um pensamento histórico etnocêntrico, conforme apontado pelo autor. A comparação estabelecida pelos alunos entre a África e o bairro Pântano do Sul, o qual é menos urbanizado do que o bairro onde está localizada a Escola Dilma Lúcia dos Santos, igualmente reforça essa perspectiva.

Além das interpretações autocentradas, outro elemento que teve destaque nas visões apresentadas pelos alunos foram as constantes referências à temática do racismo. Ademais, diversos meios de informação ressaltados também foram considerados com base em suas posturas críticas ou de reforço ao racismo, indicando que esse tema está presente nos filmes, programas de televisão, no cotidiano escolar e nos livros acessados por esses sujeitos. Além disso, levando-se em conta a metodologia de trabalho centrada no debate coletivo, os alunos também puderam apontar suas impressões pessoais sobre as ideias veiculadas 
nos diferentes meios de comunicação, destacando aproximações e afastamentos entre as perspectivas apresentadas nas diferentes mídias e suas próprias ideias.

Ao debaterem a respeito desse assunto, os alunos responsabilizaram os meios de comunicação, com destaque para os programas televisivos, como os principais propagadores de ideias racistas na atualidade. Entre os exemplos citados, o programa humorístico "Zorra Total" foi criticado por apresentar "uma personagem negra, que aparece como quem é pobre, pedindo dinheiro, e incomodando as pessoas ... mas se você perceber, ela nunca incomoda alguém da mesma cor que ela, quem ela incomoda, são sempre pessoas brancas" (S., 14 anos, $8^{\text {a }}$ série). Além desse programa, os alunos também afirmaram perceber preconceito racial nas novelas e telejornais.

Em toda a reportagem que aparece, é assim: são os negros que estão lá, traficantes. Mas bem lá atrás, são na verdade os brancos que estavam vendendo pra eles. Porque os negros foram excluídos uma época, daí eles tiveram que subir os morros e por isso hoje a maioria mora lá. (M., $8^{\mathrm{a}}$ série)

Quando eles mostravam na novela sobre negros, os negros estavam roubando, estavam matando, estavam presos, era bandido. Aí agora eles estão sendo obrigados a fazer novelas diferentes. Obrigados não! É porque o preconceito começou a ser falado, se não eles não iriam fazer nada. (L.C., $7^{\mathrm{a}}$ série)

Sobre essas duas linguagens televisivas, os alunos também criticaram seu papel na manutenção dos estereótipos de subdesenvolvimento e pobreza acerca do continente africano. Essa foi, inclusive, uma discussão reincidente durante os encontros com os pequenos grupos, na qual alguns alunos mostraram-se críticos a essa percepção, indicando exemplos de riquezas materiais, históricas e culturais oriundas da África. No entanto, outros objetaram que não era possível ter acesso a informações diversas sobre referido local, apontando novelas, filmes e noticiários como suas principais fontes para compreender a África como um continente majoritariamente pobre.

Nesses momentos, suas críticas estiveram direcionadas principalmente à televisão aberta, em especial, à Rede Globo: "Porque na minha mãe não tem NatGeo, só tem globo! E globo não passa nada de tão interessante, só passa novela" (Y., 12 anos, $6^{\circ}$ ano). Segundo A., 13 anos, do $7^{\circ}$ ano: "É assim: quando 
a Globo passa alguma coisa sobre a África mostra só como ela é pobre, como tem muitas necessidades, água, comida, coisas assim”. Segundo esse aluno, a constante referência à pobreza e violência africana na mídia brasileira é uma estratégia para encobrir a existência desses mesmos problemas no território nacional. O seguinte diálogo é representativo dessa questão:

Todo mundo pensa na África como um lugar pobre, ninguém pensa como um lugar rico em natureza e belezas como ele é. E em outras coisas também... a cultura dele é muito rica. E ninguém pensa nisso! Só pensam que é pobre com gente passando fome, que a gente tem que ajudar. Mas eu não acho que é assim. (S., $8^{a}$ série)

Como a S. disse, eu penso na África como um país pobre, porque a maioria dos documentários que eu assisto na televisão é isso, é esse o modo que eu penso. Quando eu penso em África, eu penso em uma pessoa com fome, num lugar seco. É a imagem que eu penso. Penso em uma criança negra, passando fome, no chão, sentada. E isso é triste. (I.O.P., 12, $6^{\circ}$ ano)

Em contrapartida, os alunos também destacaram experiências escolares, principalmente envolvendo as aulas de história e literatura, como espaços a partir dos quais entraram em contato com conhecimentos sobre a história e a cultura africana.

Eu acho que a escola fala muito mais de cultura. Teve um dia da consciência negra no ano passado, e foi apresentado um monte de coisas sobre a África, tinha abayomi, máscaras, tinha um monte de coisa, só sobre a África. Foi um dia só sobre a cultura africana. Tinha também um monte de trabalho que a gente fez. (L.C., $7^{\circ}$ ano)

Porque, mesmo que alguém possa falar que uma parte da família dele é 100\% alemã, eu acho que tem, lá bem escondidinho, alguma mistura com negros. Porque os negros estão na nossa história desde sempre, os negros e os indígenas. Como a professora mesmo disse, essa terra na verdade é deles. A gente é que foi lá e roubou a terra deles. Como eu disse no começo, os negros faz parte da nossa história desde sempre, desde que eu me conheço como gente. (S., $8^{a}$ série)

A professora falou que teve uma história, de que na escola os brancos sentavam na frente e os negros sentavam atrás. Aí depois que acabou o racismo, aí um menino negro perguntou se ele podia se sentar na frente, aí a professora falou 
que agora eles eram todos verdes, como ervilhas. Aí os mais claros, sentavam na frente, e os mais escuros iam para trás, continuava tudo igual. (L., $7^{\circ}$ ano)

Fundamentados nos elementos destacados sobre a história da África e dos afrodescendentes, é possível inferir, a respeito de alguns dos referenciais com base nos quais esses alunos construíram suas posturas críticas ao racismo, que as experiências escolares, com destaque para as aulas de História, estiveram presentes em diversas falas dos alunos. Dessa forma, nota-se como os integrantes do grupo, os quais possuem um interesse pessoal declarado sobre a temática, apropriam-se das narrativas didáticas acerca da história da escravidão como uma forma de subsidiar suas posturas antirracistas.

Nessa discussão, os alunos realizam um exercício de interpretação temporal, quando compreendem que no passado existiram valores e práticas considerados socialmente legítimos, os quais são condenados no tempo presente, como a questão da desigualdade racial. Segundo Rüsen (2010), por intermédio desse exercício de interpretação histórica, "uma pessoa faz parte de um todo temporal mais extenso que em sua vida temporal" (Rüsen, 2010, p.58). Nesse sentido, a orientação temporal exprime a "dimensão temporal da vida prática, descobrindo a temporalidade das circunstâncias incluídas na atividade humana". Por intermédio dessa atividade cognitiva, os sujeitos são capazes de compreender as características das diferentes temporalidades históricas como "uma consistência constitutiva das dimensões temporais da personalidade humana" (Rüsen, 2010, p.58).

Nesse sentido, considerando que a escola não é o único espaço em que os alunos constroem suas interpretações sobre a África, é possível perceber os limites do papel formador dos professores, os quais se encontram circunscritos principalmente aos espaços de escolarização. No entanto, considerando que no contexto dos alunos transitam diferentes perspectivas interpretativas sobre o continente africano, a presença da escola entre as referências elencadas não pode ser esquecida ou desvalorizada: é necessário que ela seja compreendida como um elemento ativo em meio à teia de referências presentes na elaboração do quadro interpretativo desses jovens alunos.

Por fim, considerando que os participantes apresentaram opiniões diversas a propósito das temáticas suscitadas durante as discussões, é importante considerar que foi possível constatar um movimento de interação entre as 
diferentes informações trocadas entre esses sujeitos durante as atividades desenvolvidas nos pequenos grupos. Por diversas vezes, os alunos indicaram mudanças de opinião, as quais eram justificadas pelo advento de uma nova informação trazida pelo colega, ou então por algum dos instrumentos metodológicos propostos.

Com base nessas inferências, foi possível notar que os alunos estabelecem uma mediação entre diferentes informações sobre o continente africano, as quais são relacionadas com suas experiências, de modo que esses constituem uma compreensão que se mantém aberta à reinterpretação. Assim sendo, não se trata de identificar um único espaço privilegiado de formação dos alunos sobre o tema, mas sim de compreender como são desenvolvidas as estratégias da construção das interpretações históricas desses alunos.

Esse foi um dos principais elementos percebidos na análise das atividades desenvolvidas durante a segunda etapa metodológica, na qual foi possível identificar que as múltiplas percepções que os alunos apresentam sobre o continente africano e seus descendentes são construídas e reconstruídas constantemente em seu cotidiano escolar, na interação com as diferentes mídias e também nas relações de sociabilidade estabelecidas dentro e fora dos espaços de escolarização.

\section{CONSIDERAÇÕES FINAIS}

O desenvolvimento das duas etapas metodológicas consistiu em uma trajetória processual de investigação, na qual a identificação dos apontamentos iniciais norteou os caminhos que deveriam ser aprofundados na etapa seguinte. Dessa forma, foi possível produzir um diagnóstico que considerou o conjunto dessas atividades, tomando por base as perspectivas que foram reincidentes nos diferentes momentos da inserção no campo da pesquisa. Tal estratégia de divisão das etapas metodológicas agregou significativos elementos para a análise dos dados, que puderam ser problematizados e aprofundados nos diferentes momentos de encontro com os alunos participantes.

Nas duas etapas, destacam-se as referências à África como um continente pobre e subdesenvolvido, onde é possível encontrar riquezas naturais abundantes. Na segunda etapa, ao aprofundarmos essa visão entre os alunos, foi possível perceber como ela era reforçada por programas televisivos, dentre os 
quais foram destacados filmes, jornais e novelas. Esses mesmos exemplos foram acionados quando os alunos desenvolveram críticas ao racismo, as quais foram constantes nos pequenos grupos. Ademais, também foi possível identificar posturas críticas a uma percepção homogênea a respeito do continente africano, alertando sobre sua diversidade geográfica, histórica e/ou cultural. Tal fato igualmente teve maior incidência dentre os participantes dos pequenos grupos de discussão. Essas posturas foram percebidas como sintomas do interesse pessoal dos participantes pela temática africana, reforçado também por seu envolvimento voluntário nos grupos de discussão.

Além disso, diversos alunos desenvolveram perspectivas autocentradas de interpretação quando fizeram suas considerações sobre o continente africano. Os movimentos de aproximação e distanciamento entre as características desses povos e suas próprias reforçam o papel de suas identidades e experiências no quadro interpretativo construído por esses sujeitos. Com base nessas passagens, houve a possibilidade de compreender como os alunos acionam um conjunto de experiências e informações pessoais quando procuraram estabelecer sua interpretação sobre a realidade africana.

No que concerne a esse tipo de interpretação, Rüsen (2009) destaca a necessidade de superação dessa visão hierarquizada entre "eu" e o "outro". Segundo o autor, para introduzir esse princípio, é necessário "quebrar a força da autoestima e sua sombra desvalorizadora da alteridade e dos outros. Isso demanda outra estratégia do pensamento histórico: a necessidade de integrar experiências históricas negativas na narrativa mestra de nosso próprio grupo" (Rüsen, 2009, p.179).

Com essa afirmação, cabe retomar a importância da escola na formação histórica dos alunos. Nesse mesmo sentido, o ensino de História merece ser destacado como local estratégico no qual é possível fomentar a propagação de narrativas históricas escolares mais capazes de incluir a diversidade cultural do país, agregando os diversos conflitos e relações etnorraciais que marcam a história nacional. Desse modo, trabalhando "experiências históricas negativas", conforme destaca Rüsen (2009), é possível não apenas colaborar com a superação de perspectivas históricas progressistas e autocentradas entre os alunos, como também são abaladas as estruturas do mito da democracia racial brasileira, evidenciando-se o preconceito e a opressão como marcas da nossa história. 
A percepção sobre o papel da escola na formação histórica também esteve presente nas respostas apresentadas pelos alunos, uma vez que a maioria considera esse espaço como um dos mais presentes dentre os diferentes meios por intermédio dos quais constroem seu quadro interpretativo sobre a África. As aulas de História e a Literatura Infantil destacaram-se entre tais considerações, de modo que ambas são recursos de influência decisiva pela educação das relações etnorraciais no quadro das atividades desenvolvidas na Escola Dilma Lúcia dos Santos.

Aprofundando essas reflexões, cabe por fim ressaltar que os dados identificados nesta pesquisa reforçam o delineado cada vez mais nítido de um novo desafio para a educação etnorracial. A compreensão histórica apresentada pelos alunos indica que esses sujeitos não estão completamente alheios e desprovidos de informações e interpretações sobre a África. Esse resultado direciona o foco para a questão dos tipos de interpretação que estão sendo produzidos nos espaços escolares, a fim de identificar quais dentre eles favorecem ou enfraquecem o trabalho pela construção de contextos culturalmente múltiplos e inclusivos nas escolas.

Os sentidos da interpretação histórica sobre a África que são produzidos nas escolas têm sido alvo crescente do interesse de professores e pesquisadores. Com resultado dessa tendência, destacamos a tese de Oliva (2007), um estudo comparativo entre as representações de africanos expostas na mídia e nos livros didáticos no Brasil e em Portugal. Nessa pesquisa, o autor identifica um conjunto de representações nas quais negros e africanos são retratados majoritariamente em situações de inferioridade social. Sua conclusão é que a reincidência dessa perspectiva reforça imagens estigmatizadas, que povoam o imaginário social atlântico e acabam por perpetuar relações racistas nos dois países. Dessa forma, o autor alerta para as dificuldades que envolvem a inclusão desses conteúdos nos livros didáticos, salientando a complexidade da temática e também a necessidade de reflexão constante para que seja garantido um trabalho efetivo de valorização da diversidade etnorracial nas escolas.

As conclusões de Oliva (2007), e também as que foram identificadas na presente investigação, indicam que os conteúdos históricos escolares sobre a África e os afrodescendentes continuam sendo uma questão proeminente no cenário educacional contemporâneo. A relevância da aprovação da Lei 10.639/2003 está baseada na garantia da obrigatoriedade curricular desses 
conteúdos. No entanto, o tratamento destinado aos mesmos permanece sendo uma problemática complexa. Essa constatação destaca a importância de uma vigilância constante sobre as abordagens, temáticas, recortes e metodologias selecionados, seja no que diz respeito à literatura didática, às prescrições curriculares, à formação inicial e continuada de professores, sejam no que toca às apropriações que são feitas pelos alunos com relação aos conteúdos escolares trabalhados.

Se, há cerca de uma década, a principal questão proposta para a educação das relações etnorraciais esteve centrada no empenho pelo fim do silenciamento com relação a história e cultura africana nas escolas brasileiras, atualmente o desafio parece estar concentrado na necessidade de identificar as diferentes interpretações que vêm sendo produzidas sobre o tema, desconstruindo estereótipos e agregando novos elementos para serem mediados entre sujeitos escolarizados. Isso implica dizer que em certa medida estamos superando um passado de silêncio acerca do assunto. Permanece o alerta de que, além da garantia da inclusão do assunto nas escolas, é necessário elaborar estratégias para que a diversidade histórica e cultural que constitui o continente africano e sua relação com o Brasil seja constantemente evidenciada.

Somente dessa forma será possível superar os perigos e os limites excludentes de uma história única e avançar rumo à produção de um conhecimento histórico escolar mais plural e inclusivo.

\section{REFERÊNCIAS}

ARIÈS, Philippe. O tempo da história. Trad. Roberto Leal Ferreira. Rio de Janeiro: Francisco Alves, 1989.

BRASIL. Lei no 10.639, de 9 jan. 2003. Disponível em: http://www.planalto.gov.br/ ccivil_03/leis/2003/L10.639.htm; Acesso em: 15 jun. 2014.

CERRI, Luís Fernando. Os conceitos de consciência histórica e os desafios da Didática da História. Revista de História Regional, Ponta Grossa, v.2, n.6, p.93-112, 2001. Disponível em: http://www.revistas2.uepg.br/index.php/rhr/article/ view/2133/1614; Acesso em: 7 set. 2016.

FLORIANÓPOLIS. Secretaria Municipal de Educação. Projeto Político Pedagógico Escola Básica Municipal Dilma Lúcia dos Santos. Florianópolis, 2010.

GADAMER, Hans-Georg. Problemas epistemológicos das ciências humanas. In: GA- 
DAMER, Hans-Georg; FRUCHON, Pierre (Org.) O problema da consciência histórica. Trad. Paulo Cesar Duque Estrada. Rio de Janeiro: Ed. FGV, 1998. p.17-25.

HELLER, Agnes. Uma teoria da história. Trad. Dilson Bento F. F. Lima. Rio de Janeiro: Civilização Brasileira, 1993.

OLIVA, Anderson R. Lições sobre a África: diálogos entre as representações dos africanos no imaginário ocidental e o ensino da história da África no mundo atlântico (1990-2005). Tese (Doutorado em História Social) - Universidade de Brasília (UnB). Brasília, 2007.

RÜSEN, Jörn. Aprendizagem histórica: fundamentos e paradigmas. Trad. Caio C. Pereira, Daniel Martineschen, Peter H. Rautman, Sibele Paulino. Curitiba: W. A. Editores, 2012.

Didática da História: passado, presente e perspectivas a partir do caso alemão. Trad. Marcos Roberto Kusnick. Práxis Educativa, Ponta Grossa, v.1, n.2, p.7-16, jul./dez. 2006. Disponível em: www.revistas2.uepg.br/index.php/praxiseducativa/article/download/279/285; Acesso em: 7 set. 2016.

. História Viva. Trad. Estevão de Rezende Martins. Brasília: Ed. UnB, 2007a.

. Razão Histórica. Trad. Estevão de Rezende Martins. Brasília: Ed. UnB, 2001.

. Reconstrução do passado. Trad. Asta-Rose Alcaide. Brasília: Ed. UnB, $2007 \mathrm{~b}$.

SOUZA, Maysa E. Congo e Dongo na escola: histórias na África Centro-Ocidental. In: SILVA, Cristiani B. da [et al.] (Org.) Experiências de Ensino de História no Estágio Supervisionado. Florianópolis: Ed. Udesc, 2011. p.331-349.

\section{NOTAS}

${ }^{1}$ Disponível em: https://www.youtube.com/watch?v=ZUtLR1ZWtEY; Acesso em: 22 abr. 2016.

${ }^{2}$ Visando a manter o anonimato, utilizamos iniciais do alfabeto para indicar cada aluno.

${ }^{3}$ Em referência ao bairro Pântano do Sul, localizado nas redondezas da escola.

Artigo recebido em 23 de maio de 2016. Aprovado em 8 de setembro de 2016. 